\title{
Gender Bias in Human Systemic Lupus Erythematosus: A Problem of Steroid Receptor Action?
}

\author{
Virginia Rider ${ }^{1 *}$, Nabih I. Abdou², Bruce F. Kimler ${ }^{3}$, Nanyan Lu ${ }^{4}$, Susan Brown ${ }^{4}$ \\ and Brooke L. Fridley ${ }^{5 t}$
}

'Department of Biology, Pittsburg State University, Pittsburg, KS, United States, ${ }^{2}$ Center for Rheumatic Diseases, St. Luke's Hospital, Kansas City, MO, United States, ${ }^{3}$ Department of Radiation Oncology, University of Kansas Medical Center, Kansas City, MO, United States, ${ }^{4}$ Division of Biology, Kansas State University, Manhattan, KS, United States, ${ }^{5}$ Department of Biostatistics, University of Kansas Medical Center, Kansas City, MO, United States

OPEN ACCESS

Edited by:

Carlo Selmi,

Università degli Studi di Milano, Italy

Reviewed by: Laura Andreoli, University of Brescia, Italy Edoardo Fiorillo, Istituto di Ricerca Genetica e

Biomedica (CNR), Italy

Christoph Baerwald,

University of Leipzig, Germany

*Correspondence: Virginia Rider vrider@pittstate.edu

tPresent address: Brooke L. Fridley, Department Biostatistics and Bioinformatics, Moffitt Cancer Center, Tampa, FL, United States

Specialty section:

This article was submitted to Cytokines and Soluble Mediators in Immunity, a section of the journal

Frontiers in Immunology

Received: 22 December 2017 Accepted: 12 March 2018

Published: 28 March 2018

Citation:

Rider V, Abdou NI, Kimler BF, Lu N, Brown S and Fridley BL (2018) Gender Bias in Human Systemic Lupus Erythematosus: A Problem of Steroid Receptor Action?

Front. Immunol. 9:611. doi: 10.3389/fimmu.2018.00611
Systemic lupus erythematosus (SLE) is a chronic systemic autoimmune disease resulting from abnormal interactions between T and B cells. The acquisition of SLE is linked to genetic susceptibility, and diverse environmental agents can trigger disease onset in genetically susceptible individuals. However, the strongest risk factor for developing SLE is being female ( $9: 1$ female to male ratio). The female sex steroid, estradiol, working through its receptors, contributes to the gender bias in SLE although the mechanisms remain enigmatic. In a small clinical trial, monthly administration of the estrogen receptor (ER $\alpha$ ) antagonist, ICl182,780 (fulvestrant), significantly reduced disease indicators in SLE patients. In order to identify changes that could account for improved disease status, the present study utilized fulvestrant (Faslodex) to block ER $\alpha$ action in cultured SLE T cells that were purified from blood samples collected from SLE patients $(n=18$, median age 42 years) and healthy control females ( $n=25$, median age 46 years). The effects of ER $\alpha$ antagonism on estradiol-dependent gene expression and canonical signaling pathways were analyzed. Pathways that were significantly altered by addition of Faslodex included T helper (Th) cell differentiation, steroid receptor signaling [glucocorticoid receptor (GR), ESR1 $(E R \alpha)]$, ubiquitination, and sumoylation pathways. ER $\alpha$ protein expression was significantly lower $(p<0.018)$ in freshly isolated, resting SLE T cells suggesting ER $\alpha$ turnover is inherently faster in SLE T cells. In contrast, ER $\alpha / E R \beta$ mRNA and ER $\beta$ protein levels were not significantly different between SLE and normal control T cell samples. Plasma estradiol levels did not differ $(p>0.05)$ between SLE patients and controls. A previously undetected interaction between GR and $E R \alpha$ signaling pathways suggests posttranslational modification of steroid receptors in SLE T cells may alter ER $\alpha / G R$ actions and contribute to the strong gender bias of this autoimmune disorder.

Keywords: systemic lupus erythematosus, human T cells, estradiol, estrogen receptors, glucocorticoid receptors

\section{INTRODUCTION}

Systemic lupus erythematosus (SLE) is a strongly gender-biased autoimmune disease affecting women nine times more frequently than men $(1,2)$. Onset and progression of SLE involves abnormal T cell signaling, stimulation of autoantibody production, and abnormal cytokine synthesis (3-6). The acquisition of SLE is linked to genetic susceptibility and diverse environmental agents can serve as 
triggers in genetically susceptible individuals to promote disease onset $(4,7,8)$. However, the strongest risk factor for developing SLE is being female (1). The female sex steroid, estradiol, working through its receptors, contributes to the gender bias in SLE although the mechanisms are not well-understood (9-11).

Estradiol functions by binding to specific ERs, namely ER $\alpha$ and $\operatorname{ER} \beta$, which are members of a nuclear receptor ligandregulated transcription factor family (12). Two independent genes that share a high degree of similarity in the DNA binding domain encode these receptors (13). In the classical mechanism of steroid hormone action, estradiol diffuses into target cells and binds to ERs in the nucleus (14). The ligand-activated receptors interact at specific DNA sites, termed estrogen response elements, along target genes and alter the rate of transcription $(15,16)$. Data from mice lacking ER $\alpha$ or ER $\beta$ suggest that each subtype performs specialized as well as overlapping functions to promote estradiol action in vivo (17). Male mice lacking functional $\mathrm{ER} \alpha\left(\mathrm{ER} \alpha^{-/}\right)$are resistant to developing a lupus phenotype in response to estradiol compared with their wild-type littermates suggesting $\mathrm{ER} \alpha$, rather than $\mathrm{ER} \beta$ is responsible for inducing a lupus phenotype (18). This concept is supported by more recent data suggesting $\mathrm{ER} \alpha$ promotes SLE in F1 females of a lupus mouse model $(\mathrm{NZB} \times \mathrm{NZW})(19)$.

In female patients with SLE, $\mathrm{T}$ cell levels of ER $\alpha$ protein are lower after culture in estradiol, yet, $\mathrm{T}$ cells respond robustly to a ligand $(\mathrm{ER} \alpha)$ selective agonist, 1, 3, 5-tris (4-hydroxyphenyl)4-propyl-1H-pyrazole by stimulating calcineurin and CD154 mRNA expression (20). Genomic analysis of ER binding in breast cancer cell lines $(21,22)$ indicates a substantial overlap in the chromatin binding sites for $\mathrm{ER} \alpha$ and $\mathrm{ER} \beta$ when a single receptor form is expressed. However, less overlap occurs, and, a greater number of unique binding sites are occupied, when both receptor subtypes are expressed in the same cells (21). Both receptor subtypes are expressed in human T cells (20), and the possibility exists that the receptors could form functional heterodimers when co-expressed $(23,24)$.

Steroid receptors are regulated by a large number of posttranslational modifications including phosphorylation, acetylation sumoylation, and methylation (25-28). Conjugation of the small ubiquitin-like modifier SUMO (sumoylation) to acceptor lysine residues on substrate proteins occurs in a manner analogous to ubiquitination. Free SUMO is charged and transferred to an E2 ligase enzyme (UBC9), which acts in a catalytic manner to conjugate SUMO to an acceptor lysine. Once conjugated to SUMO, the substrate conformation changes with various functional consequences including alterations in protein-protein interactions, transcription, genomic stability and intracellular trafficking (28). Sumoylation and ubiquitin pathways are mechanistically similar but involve distinct enzymes and produce different cellular effects (28-31).

The hallmark of SLE is overproduction of autoantibodies that leads to irreversible, immune complex-mediated end-organ failure. Antibody responses depend on help from $\mathrm{CD} 4^{+} \mathrm{T}$ cells that are required for the generation of germinal centers where selection of high-affinity B cells and B cell memory occurs (32). Studies in vitro indicated that Th2 cells are the major T cell subset engaged in helping B cells (33). Subsequently, T cells expressing the chemokine receptor, CXCR5, were identified as the major T cell subset that provides help to B cells (34). These follicular helper $\mathrm{T}$ (Tfh) cells are recognized as a distinct Th subset (35-37). Tfh cells secrete a unique combination of effector molecules that are critical for their development and function including high levels of ICOS, CD154, and IL-21 that promote growth, differentiation, and class-switching of B cells $(38,39)$. Humans with impaired germinal-center formation through a deficiency of CD154 or ICOS have fewer CXCR5 ${ }^{+} \mathrm{CD}^{+} \mathrm{T}$ cells (40). Targeted deletion of CD154/CD40, ICOS or IL-21 and its receptor compromises the generation of robust germinal-center reactions and impairs humoral responses $(39,40)$. Involvement of Tfh cells in shaping the effector function of B cells, and in particular, the final differentiation step in plasma cells, implicates Tfh cells as key players in immune disorders such as SLE.

In SLE T cells, signal transduction pathways are altered by estradiol compared with normal T cells (41). Previous studies in our laboratory showed that estradiol could activate and repress genes within the same signal transduction pathway (41). Of particular interest was an increase in calcineurin and CD154 expression in SLE T cell samples but not in T cell samples from control females $(9,10)$. Upregulation of these genes in SLE T cells was expected to enhance calcium-calcineurin-NFAT signaling, ultimately resulting in exaggerated help to $B$ cells and hypersecretion of autoantibodies. Consistent with this postulate was improved disease activity, and, a reduction in the expression of these $\mathrm{T}$ cell activation markers (calcineurin and CD154) in female SLE patients treated with Faslodex, a selective ER $\alpha$ antagonist (42).

The present study investigates changes in signal transduction pathways that could underlie a significant reduction in disease activity in SLE patients treated with Faslodex that we reported previously (42). The results suggest that estradiol, working through ER $\alpha$, affects the expression of genes involved in Th cell differentiation. An unexpected interaction between $\mathrm{ER} \alpha$ and GR signaling points to an intrinsic mechanism(s) in SLE T cells that alters receptor ubiquitination and sumolyation pathways. Changes in these pathways are expected to modify steroid receptor function, influence T cell development and may underlie the strong gender bias of this autoimmune disease.

\section{MATERIALS AND METHODS}

\section{Study Participants}

This study was approved by the St. Luke's Hospital Institutional Review Board and the Committee for the Protection of Human Research Subjects at Pittsburg State University. All subjects provided written informed consent prior to participation. Eighteen female patients who met the American College of Rheumatology criteria for classification of SLE (43) were enrolled in the study (Table 1). The patient's systemic lupus erythematosus disease activity index (SLEDAI) ranged from mild to severe with a median SLEDAI value of 6 (range 2-18) at the time of blood draw. Ten of the patients were Caucasian, six were African American and two were of Asian descent. The age of the patients at the time of enrollment ranged from 24 to 51 years with a median age of 42 years. The SLE patients were taking various medications including 
TABLE 1 | Systemic lupus erythematous (SLE) patient data.

\begin{tabular}{lrlcc}
\hline Sample & SLEDAl & Medications & $\begin{array}{c}\text { Disease duration } \\
\text { (years) }\end{array}$ & $\begin{array}{c}\text { Plasma estradiol } \\
\text { (pg/ml) }\end{array}$ \\
\hline SLE-1 & 4 & MMF, Pret, HCQ & 3 & 168.3 \\
SLE-2 & 9 & Pred & 9 & 98.7 \\
SLE-3 & 7 & HCQ & 5 & 90.3 \\
SLE-4 & 2 & Pred, HCQ & 10 & 86.4 \\
SLE-5 & 2 & MMF, HCQ & 12 & 128.7 \\
SLE-6 & 4 & Pred & 3 & 84.5 \\
SLE-7 & 12 & MMF & 11 & 98.4 \\
SLE-8 & 5 & Pred & 32 & 123.7 \\
SLE-9 & 4 & HCQ, Pred & 3 & 111.6 \\
SLE-10 & 16 & Pred, Cyclo & 22 & ND \\
SLE-11 & 6 & Pred, HCQ & 6 & ND \\
SLE-12 & 10 & Pred & 7 & 188.8 \\
SLE-13 & 6 & Pred, HCQ & 19 & 98.6 \\
SLE-14 & 4 & Pred & 11 & ND \\
SLE-15 & 11 & Pred, HCQ & 20 & ND \\
SLE-16 & 18 & Pred, HCQ & 15 & ND \\
SLE-17 & 4 & Pred & 9 & 95.6 \\
SLE-18 & 6 & Pred, HCQ, Aza & 20 &
\end{tabular}

Eighteen women with SLE volunteered for this study. The Systemic Lupus Erythematosus Disease Activity Index (SLEDAl) scores ranged between 2 and 18 at the time of enrollment. The patients were taking medications including mycophenolate mofetil (MMF), prednisone (Pred), hydroxychloroquin (HCQ), cyclophosamide (Cyclo), and azathioprine (Aza) as indicated. The duration of disease ranged from 3 to 32 years. Enrolled patients had regular menstrual cycles and were not taking exogenous hormones. Plasma estradiol was determined at the time of blood draw. ND, not determined.

azathioprine, mycophenolate mofetil, hydroxychloroquine, and prednisone (Pred) (Table 1). Twenty-five healthy control females were enrolled in the study. The control volunteers were between the ages of 21 and 48 with a median age of 46 years. Seventeen of the controls were Caucasian, four were African American, and four were of Asian descent. Participants had regular menstrual cycles and none of the patients or control females were taking oral contraceptives or exogenous hormone therapy at the time of blood draw. The patients and control volunteers had no history of other collagen vascular diseases.

\section{Measurement of Plasma Estradiol}

Plasma samples were isolated at the time of blood collection for T cells. Estradiol levels were measured by duplicate using a commercial ELISA plate (Estradiol ELISA 11-ESTHU-E01, ALPCO Diagnostics, Salem, NH, USA). A standard curve was used to determine the amount of estradiol in circulation at a wavelength of $450 \mathrm{~nm}$. The intra-assay coefficient of variation was $5.85 \%$.

\section{Collection of T Cell Enriched Peripheral Blood Mononuclear Cells}

$\mathrm{T}$ cell enriched mononuclear cells were separated from blood samples ( $\sim 90 \mathrm{ml}$ ) by density gradient (Histopaque, Sigma, St. Louis, MO, USA). Residual red blood cells were lysed (H-Lyse buffer, R\&D Systems, Minneapolis, MN, USA). T cells were purified by negative selection through $\mathrm{T}$ cell isolation columns (Human T Cell Enrichment Columns, R\&D Systems). The $\mathrm{T}$ cells were either used immediately (fresh $\mathrm{T}$ cell samples) or cultured overnight $(18 \mathrm{~h})$ at $37^{\circ} \mathrm{C}$ under $5 \% \mathrm{CO}_{2}$ in serum-free medium (Hybridoma, Sigma, St. Louis, MO, USA) supplemented with L-glutamine $(200 \mathrm{mM})$. Some T cells were activated after $18 \mathrm{~h}$ of culture for $4 \mathrm{~h}$ with phorbol 12 myristate 13-acetate (PMA, Sigma, $10 \mathrm{ng} / \mathrm{ml}$ ) and ionomycin (Sigma, $0.5 \mu \mathrm{g} / \mathrm{ml})$. Estradiol- $17 \beta\left(10^{-7} \mathrm{M}\right)$ was added (or not) to half of the replicate cultures for the entire culture period. We have previously shown that this dose, which is at the upper physiological range of estradiol, effectively upregulates calcineurin and CD154 expression in SLE T cells as described in detail elsewhere $(9,10)$.

\section{T47D Cell Culture}

T47D cells (ATCC, HTB-133, Manassas, VA, USA), a breast cancer cell line, which express $\mathrm{ER} \alpha$ and $\mathrm{ER} \beta$ were cultured at $37^{\circ} \mathrm{C}$ under $5 \% \mathrm{CO}_{2}$ to $80 \%$ confluence ( $75 \mathrm{~mm}$ flask) in T47D media [RPMI (Cellgro, Manassas, VA, USA)] with $200 \mathrm{mM}$ L-glutamine, 10\% fetal bovine serum (Harlan Bioproducts, Madison, WI, USA), and penicillin $(100 \mathrm{U} / \mathrm{ml})$-streptomycin $(100 \mu \mathrm{g} / \mathrm{ml})$ (Hyclone, Logan, UT, USA). The cells were released from the flask with trypsin-EDTA (Fisher Scientific, Fair Lawn, NJ, USA).

\section{RNA Isolation}

RNA was isolated from T cells and T47D cells using the TRIzol reagent (Invitrogen, Carlsbad, CA, USA) and Phase Lock Gels Heavy (Eppendorf, Fisher Scientific). Total RNA was purified from $T$ cells and treated with DNase I according to the manufacturer's protocol (DNA-free, Ambion, Austin, TX, USA).

\section{Microarray Analysis}

Gene profiling was carried out at the Kansas University School of Medicine Microarray Facility as described in detail elsewhere (41). The concentration and purity of total RNA was assessed with an Agilent Bioanalyzer and samples with RIN scores above 7.0 were used for complementary (cRNA) RNA synthesis. Biotinylated cRNA was hybridized to high density Affymetrix human GeneChips HG-U133_Plus_2, which contained 54,675 probe sets. The chips were scanned and analyzed using MAS5 type of data analysis with Affymetrix and Gene spring GX 7.3.1 (Agilent Technologies) software. Signal intensities of genes present in estradiol-treated activated T cell samples without and with Faslodex were compared to the non-treated activated $\mathrm{T}$ cell samples in order to generate a fold-change value. Differences greater than 1.5-fold were arbitrarily chosen for further study.

\section{Pathway Analysis}

Cell signaling pathways were identified using the Ingenuity Pathways Analysis (IPA, Ingenuity Systems, Redwood City, CA, USA) library of canonical pathways. The canonical pathways are manually curated algorithms that transform gene lists into relevant signal transduction networks. Gene lists comprising the data sets from SLE patient's T cells treated with and without estradiol and plus or minus Faslodex were entered into the IPA program and differences in gene expression among the treatments were matched to canonical pathways. Fischer's exact test calculated a $p$-value that determined the probability that the association between the genes in the data set (treatment) and the canonical pathway (network) were explained by chance alone. 
The top canonical pathways are those with the largest number of gene matches within a signaling network.

\section{Real-time Polymerase Chain Amplification}

Selected target genes within differentially regulated pathways were independently investigated by examining expression levels using real-time PCR. Total T cell RNA was digested using DNase 1 and cDNA was synthesized from $4 \mu \mathrm{g}$ of the resulting RNA using a High Capacity cDNA kit (Applied Biosystems, Foster City, CA, USA). Real-time PCR (Step-one, Applied Biosystems) was carried out according to the manufacturer's protocol. ER $\alpha$ and ER $\beta$ receptors were quantified from the same T cell template using a Taqman probe and ER $\alpha$ (Hs01046818, Applied Biosystems) and ER $\beta$ (Hs00230957, Applied Biosystems) primers. A Taqman probe and glyceraldehyde 3- phosphate dehydrogenase (Gapdh, Hs99999905, Applied Biosystems) specific gene primers were used for the internal control. The value of Ct was compared with a pooled T cell sample or T47D cell samples (ER $\alpha$ and $E R \beta)$ as positive controls. Samples without template were included in triplicate on each plate as a negative control. The relative expression levels were calculated by dividing the sample $\mathrm{Ct}$ values obtained from $\mathrm{T}$ cells cultured with and without estradiol from the same individual. The average $\mathrm{Ct}$ of Gapdh in untreated $\mathrm{T}$ cells was $21.8 \pm$ SEM 1.8, whereas the average Ct of Gapdh in hormonally stimulated T cells was $22.3 \pm$ SEM 1.5 , indicating no change in response to treatment.

\section{Isolation of T Cell Proteins}

Total RNA and proteins were sequentially separated from the same freshly isolated $\mathrm{T}$ cell samples by column purification (Norgen Biotek, ON, Canada). Briefly, RNA was bound to the column and the proteins were collected in the flow through. RNA was treated with DNase I and eluted from the column. The $\mathrm{pH}$ of the flow through was adjusted, the proteins were bound to the column, and the columns were washed. The proteins were eluted and stored at $-80^{\circ} \mathrm{C}$.

\section{Western Blot Analysis}

Purified protein samples were heated at $95^{\circ} \mathrm{C}$ for $5 \mathrm{~min}$. Total $\mathrm{T}$ cell proteins were size fractionated by sodium dodecyl sulfate polyacrylamide gel electrophoresis (SDS-PAGE, 10\%). The T47D cell extract was used for a positive control for ER $\alpha$ and $\operatorname{ER} \beta$ while the lysis solution served as a negative control. Proteins were transferred electrophoretically $(18 \mathrm{~h}, 12 \mathrm{~V})$ onto nitrocellulose membranes using Transblot buffer (25 mM Tris-HCL, pH 8.3, $192 \mathrm{mM}$ glycine, and 20\% methanol). After the protein transfer, non-specific protein binding sites were blocked with Superblock buffer (\# 37515, Thermo Scientific, Rockford, IL, USA) for $1 \mathrm{~h}$ with gentle shaking. The membranes were incubated with an ERa rabbit polyclonal antibody (sc-542, Santa Cruz Biotechnology, Santa Cruz, CA, USA) in a 1:1,000 dilution for $1 \mathrm{~h}$, and washed four times ( 5 min each) with wash buffer $(1 \times$ PBS containing $0.05 \%$ Tween-20). The membrane was incubated with horseradish peroxidase-conjugated goat anti-rabbit IgG $(10 \mu \mathrm{g} / \mathrm{ml}, 32460$, Thermo Scientific, Rockford, IL, USA) at 1:4,000 dilution for $1 \mathrm{~h}$. The blots were washed four times ( $5 \mathrm{~min}$ each) with wash buffer. The blot was incubated in a chemiluminescent reagent
(Super Signal West Femto Maximum Sensitivity Substrate kit, 34096, Thermo Scientific, Rockford, IL, USA) for $5 \mathrm{~min}$ and exposed to chemiluminescent film (Kodak, BioMax) for 4-5 min. Blots were stripped with Restore Western Blot Stripping Buffer (Pierce, Rockford, IL, USA) for $15 \mathrm{~min}$ at $37^{\circ} \mathrm{C}$ to remove antibody. The membrane was exposed to chemiluminescent film for $5 \mathrm{~min}$ to ensure removal of the primary antibody. The membrane was reacted with ER $\beta$ antibody (sc-8974, Santa Cruz Biotechnology, Santa Cruz, CA, USA, 1:250 dilution) for $1 \mathrm{~h}$. The membrane was incubated with horseradish peroxidase-conjugated goat anti-rabbit IgG $(10 \mu \mathrm{g} / \mathrm{ml}, 32460$, Thermo Scientific, Rockford, IL, USA, 1:4,000) for $1 \mathrm{~h}$ at $22^{\circ} \mathrm{C}$ with gentle shaking. The blot was incubated with Super Signal West Femto Maximum Sensitivity kit reagent for $5 \mathrm{~min}$ and the membrane was exposed to Biomax film for 4-5 min. The membrane was stripped and incubated with a $\beta$-actin antibody $(2 \mathrm{mg} / \mathrm{ml}, \mathrm{A} 5441$, Sigma, St. Louis, MO, USA, 1:6,000) for $1 \mathrm{~h}$. The blots were washed and reacted with peroxidase-conjugated goat anti-mouse antibody $(10 \mu \mathrm{g} / \mathrm{ml}$, 32430, Thermo Scientific, Rockford, IL, USA) at a 1:4,000 dilution for $1 \mathrm{~h}$. The blot was incubated with chemiluminescent substrate and exposed to Biomax film for approximately $10 \mathrm{~s}$. The amount of receptor was determined using scanning densitometry (Kodak Gel Logic). The optical density of ER $\alpha$ and ER $\beta$ protein was divided by the optical density of $\beta$-actin on the same blot. Scanning densitometry of $\beta$-actin across assays did not vary more than $10 \%$ verifying its lack of response to treatment.

\section{Statistical Analysis}

Samples from each subject enrolled in this study were not tested in all assays because the entire blood draw was required for each assay. Gene chips were normalized and a Student's $t$-test was used to compare differences in $\mathrm{T}$ cell gene expression without estradiol and/or Faslodex and with estradiol and/or Faslodex. Comparison of differences in ER $\alpha / E R \beta$ and CXCR5 expression were assessed using a nonparametric Mann-Whitney $U$ test. A $p$-value $<0.05$ (two-sided) was considered statistically significant.

\section{RESULTS}

Global changes in gene expression were compared between peripheral blood T cells of SLE patients $(n=9)$ cultured with and without estradiol in order to identify differential effects of estradiol on signaling pathways. The top five canonical pathways altered by estradiol treatment included Th cell differentiation, GR signaling, immune cell signaling in rheumatoid arthritis, cytokine communication between immune cells, and phospholipase $\mathrm{C}$ signaling (Table 2). The top five downstream genes altered by estradiol and shared among these canonical pathways are shown in Table 2. TNF and TGF- $\beta 1$ were shared among four of the top five signaling pathways. IL-21 and NFATC3 were shared among two of the top five canonical pathways. Since the data were obtained from SLE T cells, we investigated if estradiol altered the canonical SLE signaling pathway. Estradiol changed gene expression in the SLE signaling pathway $\left(\mathrm{p}=4.8 \times 10^{-3}\right)$, though this pathway was not among the top five significant pathways affected. Two candidate downstream genes, NFATC3 and TNF were shared between SLE and GR signaling pathways (Table 2). 
TABLE 2 | The top five canonical signal transduction pathways affected by estradiol in activated systemic lupus erythematosus (SLE) T cells.

\begin{tabular}{lll}
\hline Pathway & $\begin{array}{c}\text { SLE + E vs } \\
\text { SLE - E }\end{array}$ & $\begin{array}{l}\text { Shared downstream } \\
\text { genes (pathway) }\end{array}$ \\
\hline 1- T helper cell differentiation & $2.7 \times 10^{-8}$ & $\operatorname{TGF}-\beta 1(1,2,3,4)$ \\
2- Glucocorticoid Receptor Signaling & $1.1 \times 10^{-7}$ & $\operatorname{TNF}(1,2,3,4,6)$ \\
3- Role of macrophages, fibroblasts, and, & $1.5 \times 10^{-7}$ & $\operatorname{IL}-21(1,3,4)$ \\
$\quad$ endothelial cells in rheumatoid arthritis & & $\operatorname{NFATC3}(2,5,6)$ \\
4- Role of cytokines in mediating & $1.9 \times 10^{-6}$ & $\operatorname{RAF1}(2,5)$ \\
$\quad \begin{array}{l}\text { commmnicalion between immune cells } \\
\text { 5- Phospholipase C Signaling }\end{array}$ & $3.2 \times 10^{-6}$ & \\
6- SLE signaling & $4.8 \times 10^{-3}$ & \\
& &
\end{tabular}

SLE T cell samples $(n=9)$ were cultured without and with estradiol. The T cells were activated as described in the text. Changes in global gene expression was profiled using microarray analysis. Gene lists were generated from the microarray data and pathways that were altered by estradiol were identified by Ingenuity Pathway Analysis. The p-value of overlap is shown for each pathway. Major downstream genes affected by estradiol treatment were variably shared among the pathways (shown in parentheses).

${ }^{a}$ Although the canonical SLE signal transduction pathway was affected by estradiol it was not within the top five.

The expression of the chemokine receptor, CXCR5 was different between SLE T cells treated without and with estradiol only in the Th cell differentiation pathway. Owing to the importance of CXCR5 in T-B cell interactions, we further quantified CXCR5 expression in SLE patient $\mathrm{T}$ cell samples $(n=12)$ cultured without and with estradiol using real-time PCR (Figure 1). In 3 of the 12 SLE T cell samples investigated, CXCR5 expression increased robustly (samples $5,9,16)$ in response to estradiol. The SLEDAI scores for those patients 2 (mild), 4 (moderate), and 18 (active) ranged from mild to severe. There was no correlation between disease activity and CXCR5 expression in the patients. The relative median expression of CXCR5 in SLE T cells was 1.1. In the control T cell samples $(n=12)$, CXCR5 expression did not change in response to estradiol (Figure 1). CXCR5 expression in the $\mathrm{T}$ cells from control females was generally unaffected by estradiol with a median relative expression of 0.9 , similar to that for $\mathrm{T}$ cell samples from the SLE patients (Figure 1). Interestingly, relative CXCR5 expression varied in the SLE T cell samples with both lower and higher expression values compared to those from the control $\mathrm{T}$ cell samples.

Administration of the ER $\alpha$ antagonist Faslodex to SLE patients in a small clinical trial significantly reduced their SLEDAI scores (42). It was of interest, therefore, to identify signaling pathways that could account for disease improvement when ER $\alpha$ action was blocked by Faslodex. We compared SLE T cell samples $(n=9)$ cultured with Faslodex to the same T cell samples cultured without Faslodex (Table 3). In a separate set of experiments, we added estradiol to the SLE T cell cultures $(n=9)$ without and with Faslodex (Table 4). In the absence of added estradiol, the top canonical pathways affected by Faslodex are shown in Table 3. Addition of estradiol to the T cells cultured without and with Faslodex changed some of the top pathways affected (Table 4). It is notable, that GR signaling was a top canonical pathway affected by estradiol without and with added Faslodex (compare Tables 2-4). A striking relationship emerged for the top upstream regulators in SLE T cells treated with Faslodex,

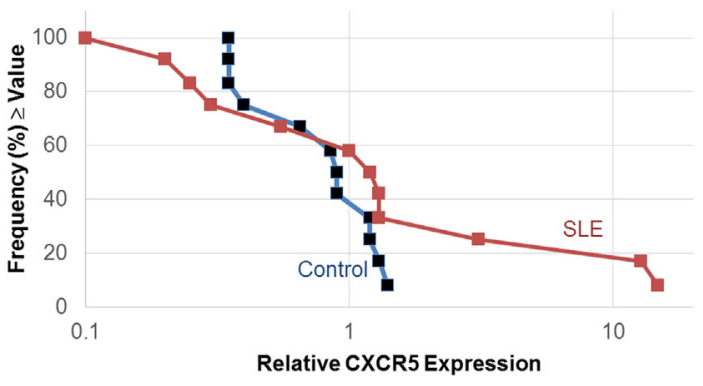

FIGURE 1 | Estradiol effects on CXCR5 expression in activated systemic lupus erythematosus (SLE) T cells. Human T cells were isolated as described in the text and cultured in serum-free medium without and with estradiol. The relative amount of CXCR5 expression following activation was measured by real-time PCR. Data shown are the frequency of $T$ cell samples from controls $(n=12)$ and SLE patients $(n=12)$ that exhibited relative CXCR5 expression values that were at or above the value on the $x$-axis.

TABLE 3 | The top five canonical pathways affected by the estrogen receptoralpha $(E R \alpha)$ antagonist, Faslodex, in activated systemic lupus erythematosus (SLE) T cells.

\begin{tabular}{lcl}
\hline Pathway & $\begin{array}{c}\text { SLE-E + F vs } \\
\text { SLE-E }\end{array}$ & $\begin{array}{l}\text { Tap upstream } \\
\text { regulators }\end{array}$ \\
\hline Glucocorticoid receptor signaling & $2.8 \times 10^{-6}$ & HNF4A \\
Sumoylation pathway & $2.2 \times 10^{-5}$ & MVC \\
Purine nucleotides biosynthesis II & $8.6 \times 10^{-5}$ & ESR1 \\
Estrogen receptor signaling & $1.1 \times 10^{-4}$ & CSTS5 \\
Cleavage and polyadenyladon of Pre-mRNA & $1.8 \times 10^{-4}$ & MMP3 \\
SLE signalinga & $7.7 \times 10^{-4}$ & \\
\hline
\end{tabular}

SLE T cell samples ( $n=9$ ) were cultured without and with Faslodex and activated as described in the text. Gene lists were generated from microarray data and analyzed for canonical signaling pathways altered by Faslodex. The $p$-value of overlap is shown for each pathway.

aAlthough the canonical SLE signal transduction pathway was affected by Faslodex, it was not within the top five. MMP3 was a unique top upstream regulator in the T cells treated with Faslodex without estradiol addition.

TABLE 4 | The top five canonical pathways affected by the estrogen receptoralpha $(E R \alpha)$ antagonist, Faslodex in activated systemic lupus erythematosus (SLE) T cells $(n=9)$ cultured with estradiol was determined.

\begin{tabular}{lcl}
\hline Pathway & $\begin{array}{c}\text { SLE + E + F vs } \\
\text { SLE + E }\end{array}$ & $\begin{array}{l}\text { Top Upstream } \\
\text { Regulators }\end{array}$ \\
\hline Glucocorticoid receptor signaling & $1.1 \times 10^{-16}$ & MYC \\
EIF2 signaling & $3.8 \times 10^{-15}$ & HNF4A \\
Hereditary breast cancer signaling & $1.6 \times 10^{-11}$ & ESR1 \\
Protein ubiquitination pathway & $9.6 \times 10^{-10}$ & CSTS5 \\
JAK/Stat Signaling & $1.4 \times 10^{-9}$ & TP53 \\
SLE signalinga & $3.4 \times 10^{-8}$ & \\
\hline
\end{tabular}

Gene lists were generated from microarray data and analyzed for canonical signaling pathways altered by Faslodex. The p-value of overlap is shown for each pathway. ${ }^{a}$ Although the canonical SLE signal transduction pathway was affected by Faslodex plus estradiol, it was not within the top five. TP53 was a unique top upstream regulator in the T cell samples treated with Faslodex with estradiol addition.

regardless of estradiol addition or not. The principal regulators shared among Faslodex treated T cells included MYC, HNF4A, ESR1, and CST5 (Tables 3 and 4). Downstream genes affected by ER $\alpha$ antagonism and shared among the Faslodex treatments, 
regardless of added estradiol, included AKT3, CBL, cyclic AMP responsive element modulator (CREM), FOS, JUN, and NFAT5. In the absence of added estradiol, MMP3 was a unique upstream regulator (Table 3), while addition of estradiol to cultures revealed TP53 as a unique regulator (Table 4). The SLE canonical signaling pathway was significantly altered in SLE T cells cultured in Faslodex containing medium without $\left(7.7 \times 10^{-4}\right)$ and with $\left(3.4 \times 10^{-8}\right)$ estradiol, though it was not one of the top five canonical pathways.

ER antagonism altered the ubiquitination (SLE T cells + estradiol + Faslodex vs SLE T cells + estradiol) pathway in SLE T cells. This pathway was of particular interest because ubiquitin enzymes are essential for regulation of T cell, B cell, and TNF signaling cascades (44). Moreover, activated SLE T cells cultured in medium containing estradiol express less ER $\alpha$ protein than T cell samples from healthy women cultured under the same conditions (20). Investigation of the downstream genes that differed between SLE T cells cultured with estradiol and treated without and with Faslodex revealed changes in 57/255 genes in the ubiquitination pathway (data not shown). The affected genes included ubiquitinactivating enzymes (E1), conjugating enzymes (E2), ligases (E3 HECT), and deubiquitinases. Several factors within the immunoproteosome were altered and the transporter associated with antigen processing (TAP) differed in SLE T cells treated with Faslodex compared with untreated SLE T cells.

$\mathrm{ER} \alpha$ antagonism altered sumolyation (SLE T cells - estradiol + Faslodex vs SLE T cells - estradiol) signaling in SLE T cells. Within the sumoylation pathway, the expression of 27/96 genes were affected by Faslodex treatment. Investigation of the genes involved, revealed expression of SUMO-1, FAS, RANBP2 and GR as candidates modified by Faslodex treatment. Since Faslodex altered GR signaling in all SLE T cells, we also compared the data sets to determine which key downstream genes were altered. Faslodex changed the expression of 62 genes $(62 / 282)$ in the absence of added estradiol and 76 genes (76/287) when estradiol was added to the activated SLE T cell cultures (data not shown). Changes in key downstream genes revealed differences in SUMO-1 and UBE21 (UBC9) expression (data not shown). SUMO-1 and UBC9 target nuclear hormone receptors and their ability to modulate transcription.

To test if protein turnover of ER $\alpha$ was modified in SLE T cells, we compared mRNA and protein levels in freshly isolated T cells from SLE patients and control females. Receptor mRNA and protein were quantified in nine freshly isolated SLE T cell samples (Table 5) and 10 freshly isolated control T cell samples (Table 6). Comparison of the amount of ER $\alpha$ subtype mRNA revealed no significant differences $(p=0.97)$ between SLE patient and control $\mathrm{T}$ cell samples. The median relative value for ER $\alpha$ mRNA in SLE T cell samples was 0.027 (Table 5) while the median relative value in control T cell samples was 0.045 (Table 6). Comparison of the amount of ER $\beta$ subtype mRNA revealed no significant differences ( $p=0.18$ ) between SLE patient and control T cell samples. The median relative value for ER $\beta$ mRNA in the SLE T cell samples was 0.6 (Table 5) while the median value in the control $\mathrm{T}$ cell samples was 2.5 (Table 6). The difference in the ratio of ER $\alpha$ : ER $\beta$ mRNA between the control and SLE T cell samples approached significance $(p=0.065)$, even though the ratio was less than
TABLE 5 | Measurements of ER subtype mRNA and protein in freshly isolated systemic lupus erythematosus (SLE) T cells.

\begin{tabular}{|c|c|c|c|c|c|}
\hline \multirow[t]{2}{*}{ Samples } & ERa & ER $\beta$ & ERa & ER $\beta$ & \multirow{2}{*}{$\begin{array}{c}\text { Estradiol } \\
\mathrm{pg} / \mathrm{ml}\end{array}$} \\
\hline & \multicolumn{2}{|c|}{ (mRNA) } & \multicolumn{2}{|c|}{ (Protein) } & \\
\hline SLE-1 & 0.036 & 0.811 & 0.62 & 0.61 & 166.3 \\
\hline SLE-2 & 0026 & 0.170 & 0.35 & 0.85 & 98.7 \\
\hline SLE-3 & 0.018 & 0.443 & 0.93 & 0.80 & 90.3 \\
\hline SLE-4 & 0.027 & 0.442 & 0.29 & 0.67 & 86.4 \\
\hline SLE-5 & 0.083 & 1.365 & 0.40 & 0.87 & 128.7 \\
\hline SLE-6 & 0.071 & 0.370 & 1.00 & 0.90 & 84.5 \\
\hline SLE-7 & 0.015 & 0.660 & 0.31 & 0.65 & 98.4 \\
\hline SLE-8 & 0024 & 0.600 & 0.80 & 0.98 & 123.7 \\
\hline SLE-9 & 0.238 & 18.15 & 0.76 & 0.98 & 111.6 \\
\hline Median & 0.027 & 0.60 & 0.62 & 0.85 & 98.7 \\
\hline
\end{tabular}

Blood samples were drawn from SLE patients $(n=9)$ and T cells were purified by negative selection. ER subtype mRNA was measured by real-time PCR and protein in the same T cell sample was quantified by Western blotting. Plasma estradiol was measured at the time of blood draw. The levels of hormone in circulation were within the normal range for women with regular menstrual cycles.

SLEDAl, systemic lupus disease activity index.

TABLE 6 | Measurements of ER subtype mRNA and protein in freshly isolated systemic lupus erythematosus $T$ cells.

\begin{tabular}{lllllrr}
\hline \multirow{2}{*}{ Samples } & ERa & ER $\beta$ & & ERa & ER $\beta$ & $\begin{array}{r}\text { Estradiol } \\
\text { (pg/ml) }\end{array}$ \\
\cline { 2 - 3 } & \multicolumn{2}{c}{ (mRNA) } & & (Protein) & \\
\hline CTRL 1 & 0.068 & 7.40 & & 1.10 & 0.88 & 99.5 \\
CTRL 2 & 0.020 & 0.63 & & 1.00 & 0.92 & 156.5 \\
CTRL 3 & 0.004 & 0.08 & & 1.60 & 1.60 & 88.9 \\
CTRL 4 & 0.030 & 2.70 & & 0.90 & 1.20 & 133.3 \\
CTRL 5 & 0.008 & 0.30 & & 1.10 & 1.40 & 99.6 \\
CTRL 6 & 0.009 & 3.70 & & 0.67 & 0.08 & 124.8 \\
CTRL 7 & 0.060 & 4.70 & & 0.83 & 1.20 & 143.9 \\
CTRL 8 & 0.147 & 1.80 & & 0.81 & 0.97 & 125.7 \\
CTRL 9 & 0.090 & 2.20 & & 0.63 & 0.46 & 121.5 \\
CTRL 10 & 0.270 & 7.50 & & 1.10 & 1.00 & 93.3 \\
\hline Median & 0.045 & 2.5 & & 0.97 & 0.99 & 123.1 \\
\hline
\end{tabular}

Blood samples were drawn from healthy volunteers $(n=10)$ and T cells were purified by negative selection. ER subtype mRNA was measured by real-time PCR and protein in the same T cell sample was quantified by western blotting. Plasma estradiol was measured at the time of blood draw. The levels of hormone in circulation were within the normal range for women with regular menstrual cycles.

SLEDAl, systemic lupus disease activity index.

unity for all samples in both groups. The median concentration of estradiol in plasma was similar $(p=0.28)$ between the SLE patients (97 pg/ml, Table 5) and the control females $(123 \mathrm{pg} / \mathrm{ml}$, Table 6). Those values are within the normal range for women with regular menstrual cycles.

We next analyzed ER subtype protein expression in the same $\mathrm{T}$ cell samples. Incubation of western blots with $\mathrm{ER} \alpha$ antibody revealed a single reactive protein that migrated at approximately $65 \mathrm{kDa}$, consistent with the size for $\mathrm{ER} \alpha$ protein (Figure 2). After the membrane was stripped and reacted with ER $\beta$ antibody a single reactive protein was identified at approximately $56 \mathrm{kDa}$, consistent with the size of ER $\beta$ (Figure 2). The membrane was stripped and reacted with $\beta$-actin antibody and a single reactive protein was observed at a molecular size of approximately $42 \mathrm{kDa}$, consistent with the size for $\beta$-actin. In the absence of $\mathrm{T}$ cell extract, no reactive proteins were observed (data not shown). 


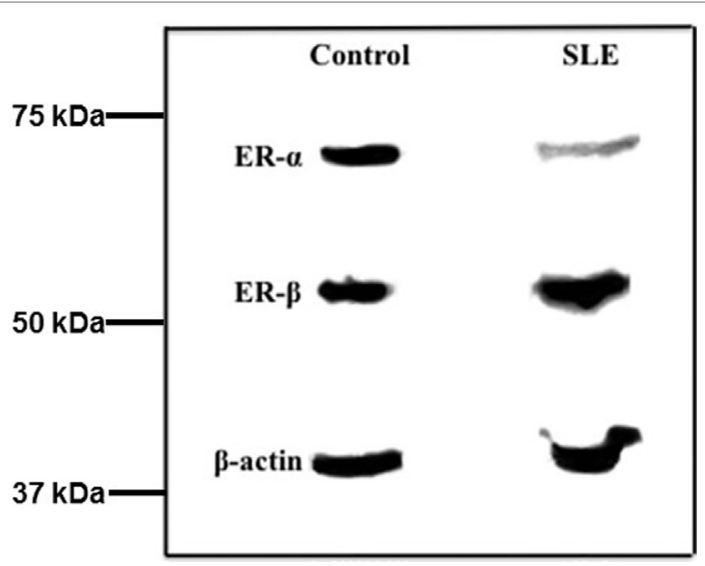

FIGURE 2 | Western blots of freshly isolated T cell proteins indicate the amount of ER $\alpha$ but not ER $\beta$ is less in systemic lupus erythematosus (SLE) patients compared with female controls. Fresh $T$ cell extracts were size fractionated by SDS-PAGE and transferred to nitrocellulose membranes. The blots were sequentially reacted with antibodies to $E R \alpha, E R \beta$, and $\beta$-actin. The relative amount of receptor subtype was measured by scanning densitometry and values were adjusted to $\beta$-actin in the same T cell sample.

TABLE 7 | Comparison of the relative expression of estrogen receptor subtypes (ER $\alpha: E R \beta)$ for protein:mRNA ratios indicates lower values in the systemic lupus erythematosus (SLE) T cell samples.

\begin{tabular}{lccc}
\hline Parameter & $\begin{array}{c}\text { Medlar } \\
\text { control }\end{array}$ & $\begin{array}{c}\text { Values } \\
\text { SLE }\end{array}$ & $\begin{array}{c}\boldsymbol{p} \text {-Value } \\
\text { (Mann-Whitney) }\end{array}$ \\
\hline Ratio of protein:mRNA (ER $\alpha)$ & 23 & 14 & 0.37 \\
Ratio of protein:mRNA (ER $\beta$ ) & 0.3 & 1.5 & 0.14 \\
Ratio of protein:mRNA (ERa:ERp) & 34 & 21 & 0.018 \\
\hline
\end{tabular}

These results suggest accelerated turnover of ER $\alpha$ in SLE T cells.

Comparison of the amount of $\mathrm{ER} \alpha$ protein revealed a significant difference $(p=0.010)$ between SLE patient and control $\mathrm{T}$ cell samples. The median relative value in SLE T cell samples was 0.62 (Table 5) while that for $\mathrm{ER} \alpha$ protein in control $\mathrm{T}$ cell samples was 0.97 (Table 6). There was no significant difference in the median values for ER $\alpha$ between patients with mild disease (median value 0.56, SLEDAI $\leq 4$ ) and those with greater disease activity (median value 0.61, SLEDAI $\geq 5$ ). Comparison of the amount of ER $\beta$ subtype protein revealed no significant differences $(p=0.11)$ between SLE patient and control T cell samples. The median relative value in SLE T cell samples was 0.85 (Table 5) while the median relative value for $\operatorname{ER} \beta$ protein in control $\mathrm{T}$ cell samples was 0.99 (Table 6). The ratio of ER $\alpha$ : ER $\beta$ protein was a median of 0.78 in the SLE T cell samples and 1.05 in the control $\mathrm{T}$ cell samples, respectively. The difference in the ratio of ER $\alpha$ : ER $\beta$ protein between the SLE and the control T cell samples was not significant $(p=0.079)$.

Comparison of the ratio of protein to mRNA (designated as the relative productivity) showed all ratios $>1$ for ER $\alpha$ while ratios for $\operatorname{ER} \beta$ were $<1$ in the majority $(11 / 19)$ of samples. The relative productivity of $\mathrm{ER} \alpha$ was always greater than for $\mathrm{ER} \beta$, but these did not differ between the two cohorts (Table 7). However, a comparison of the relative subtype expression $(\operatorname{ER} \alpha: E R \beta)$ for the protein:mRNA ratios between the SLE T cell samples and the normal $\mathrm{T}$ cell samples revealed lower values in the SLE T cell samples ( $p=0.018$, Table 7$)$. The primary factor associated with $\mathrm{ER} \alpha$ protein was $\mathrm{ER} \beta$ protein $(p=0.006)$. The second factor associated with $\mathrm{ER} \alpha$ protein was experimental group (cohort, i.e., SLE $\mathrm{T}$ cell samples vs control T cell samples).

\section{DISCUSSION}

The present study investigated global cell signaling changes in human SLE T cells treated with estradiol and the ER $\alpha$ antagonist, Faslodex. We compared the effects of blockading the action of ER $\alpha$ in order to identify signaling pathways that could contribute to improved disease activity in women with SLE we reported previously (42). Estradiol altered gene expression in pathways involved in Th cell differentiation, ER $\alpha / G R$ signaling and immune cell interactions. Antagonism of ER $\alpha$ by Faslodex revealed changes in protein ubiquitination and protein sumoylation pathways. We found that ER $\alpha$ protein but not mRNA was lower in SLE T cells compared with $\mathrm{T}$ cells from healthy individuals, suggesting more rapid turnover of ER $\alpha$ in SLE T cells. The results are consistent with the concept that turnover of $\mathrm{ER} \alpha$ is accelerated in SLE $\mathrm{T}$ cells and may occur through alterations in the ubiquitination signaling pathway. Antagonism of ER $\alpha$ affected the sumoylation pathway and SUMO-1 and UBC9 expression were changed in GR signaling. Modification in these signaling pathways could account for the significant improvement of disease activity in SLE patients receiving monthly Faslodex treatments (42). Additional experiments are required to determine how changes of steroid receptors could alter signal transduction pathways in SLE T cells as suggested by the current results.

ER $\propto$ protein levels are lower in SLE T cells compared with normal T cells although ER $\alpha$ mRNA and ER $\beta$ mRNA and protein are similar between SLE T cell samples and control T cell samples. The molecular basis for the difference in ER $\alpha$ protein levels remains to be established but the current results suggest ER $\alpha$ turnover accelerates owing to changes in the ubiquitination pathway. The half-life of ER $\alpha$ protein is short $(\sim 4 \mathrm{~h})$ in primary uterine cells and breast cancer cell lines in culture (45). Consistent with other short-lived regulatory proteins, ER $\alpha$ turnover occurs through the 26 S proteasome system (46-48). In spite of the shared structural similarities between the receptors, our results suggest that ER $\alpha$ and not $\operatorname{ER} \beta$ is the target for accelerated turnover. A recent study in breast cancer cell lines revealed the $S$-phase kinase-associated protein $2(S k p 2)$, which is a substrate recognition component of the SC ubiquitin ligase complex, targets ER $\alpha$ but not ER $\beta$ for degradation (49). The basis of this difference resides in a serine residue (serine 294), which is phosphorylated in ER $\alpha$ by p38MAPK and is not present in ER $\beta$. In SLE T cells treated with Faslodex, MAPK expression was altered in the ER $\alpha$ signaling pathway (data not shown). However, patterns of ER $\alpha$ phosphorylation, activation and turnover require additional analyses in $\mathrm{T}$ cells. Since appropriately timed destruction of ER $\alpha$ is essential for its function, it is now important to investigate potential posttranslational modifications of $\mathrm{ER} \alpha$ that may accelerate receptor turnover in SLE T cells and change the transcriptional activity of the receptor. 
SUMO modification of ER $\alpha$ and GR alters protein-protein interactions and transcriptional profiles $(25,28,50)$. The enzyme, UBC9, is the only known E2 SUMO-conjugating enzyme that is necessary for SUMO attachment to substrate proteins $(28,30,31)$. Comparison of SLE T cells cultured with estradiol and Faslodex to the same T cell sample cultured with estradiol alone (Table 4), revealed changes in GR signaling. Downstream genes affected in the GR canonical signaling pathway included Sumo1 and Ubc9. Estradiol increased UBC9 expression in MCF-7 breast cancer cells while ICI182,780 abrogated the response $(51,52)$. Ubc9 deletion in T regulatory (Treg) cells results in early-onset lethal autoimmune disorders (53). Loss of $U b c 9$ downregulated a variety of cytokine, chemokine and IL-1 receptor activity suggesting that sumoylation is required for proper immune function of Treg cells. Mice deficient in $U b c 9$ show perturbations in early T cell maturation in the thymus and a reduction in the nuclear localization of NFAT in response to PMA-ionomycin activation (54). The results from our study suggest ER $\alpha$ antagonism changes the expression of genes involved in GR signal transduction in SLE T cells. To our knowledge, interaction between ER and GR signaling has not been studied in SLE T cells. However, in murine mammary cells chromatin accessibility is enhanced by activation of the opposite receptor (55), GR activation can displace ER from AP-1 sites (56), and ER and GR may act cooperatively at DNA regulatory sites (57). Disruption of GR signaling results in inflammation characterized by increased cytokines in the blood (58). The results from our study suggest that interaction between ER $\alpha$ and GR occurs in SLE T cells when ER $\alpha$ action is blocked. Increased understanding about the molecular basis of this interaction could explain the improvement in SLE patient's disease activity when Faslodex was administered monthly to SLE patients.

Antibody responses depend on help from $\mathrm{CD}^{+} \mathrm{T}$ cells that are required for the generation of germinal centers where selection of high-affinity B cells and B cell memory occurs (32). Expression of CXCR5, when coupled with loss of the T cell zonehoming chemokine receptor CCR7, allows Tfh cells to relocate from the $\mathrm{T}$ cell zone to the $\mathrm{B}$ cell follicles, where they support B cell expansion and differentiation (59). In the present study, estradiol increased CXCR5 expression in $25 \%$ of the $\mathrm{T}$ cells from SLE patients. The difference in expression was primarily due to three $\mathrm{T}$ cell samples in which, expression levels robustly responded to estradiol. We did not find a correlation between CXCR5 expression and SLEDAI scores, but our study measured relative expression rather than the number of CRCR5 ${ }^{+}$cells. Tfh cells in circulation constitute a small subset of total immune cells in the blood. Thus, it is possible that the median change in CXCR5 expression in circulating $\mathrm{T}$ cells is due to an increase in the number of cells expressing CXCR5 but additional experiments are necessary to resolve this question. Dysregulation of Tfh cells that promotes B cell activation is associated with SLE-like disease in the roquin san/san mouse $(60,61)$. This mouse model arose from a mutation in the ubiquitin ligase roquin that disrupts a repressor of ICOS, an essential stimulator of Tfh cells. Analysis of $\mathrm{CXCR}^{+}{ }^{+} \mathrm{CD} 4{ }^{+}$cells expressing high levels of Tfh-associated molecules, revealed a subset of SLE patients who showed increased Tfh cells in circulation. The increased Tfh cells correlated with the diversity and titers of autoantibodies and with the severity of end-organ involvement (62). Analysis of global gene expression in this study, indicate Th cell differentiation is affected by ER $\alpha$ antagonism. Since CXCR5 is a defining marker for Tfh cells, we explored changes in CXCR5 expression in SLE T cells. The results are equivocal because only 3 out of 12 SLE T cell samples were estradiol responsive. Moreover, Th responses can be mediated by Th1/Th2 and Th17 subsets $(35,37,63)$. In order to define the role of ER $\alpha$ in Th differentiation, analysis of Th subsets and downstream effector functions are necessary.

Systemic lupus erythematosus is a multifactorial autoimmune disorder with numerous cellular abnormalities and clinical presentations. The unifying theme among SLE T cell dysfunction is a loss of the ability to sense antigenic signals and properly integrate these signals within the adaptive and innate immune systems. While progress has been made in understanding the molecular basis and genetic susceptibility for SLE, the strong gender bias in the disorder remains an enigma. The present study indicates a significant decline in the amount of ER $\alpha$ protein in resting SLE $\mathrm{T}$ cells relative to resting normal T cells. Alterations in the balance of $E R \alpha$ and $E R \beta$ will profoundly affect hormone-responsiveness of target cells as suggested from global analyses of ER subtype binding across the genome. Analysis of global changes in gene expression when we blocked ER $\alpha$ function with Faslodex in SLE $\mathrm{T}$ cells indicates both protein ubiquitination and sumoylation pathways are affected. Faslodex identified an unsuspected interaction between ER $\alpha$ and GR signaling. Steroid receptor function requires appropriately time destruction and sumoylation of receptors. The present results suggest that posttranslational modification of steroid receptors (ER $\alpha / \mathrm{GR})$ in SLE T cells may be aberrant. These alterations are likely to affect numerous pathways and lead to signaling dysfunction of SLE T cells.

In this study, we have focused on female SLE patients with regular menstrual cycles who were not taking exogenous estradiol. Although the study design controlled for exogenous estradiol effects, SLE is a heterogeneous autoimmune disorder with numerous clinical presentations. Current therapeutic agents used to treat SLE are based on patterns of end-organ appearance rather than from understanding the molecular basis of the disease. Since the goal of this study was to assess the importance of estradiol in SLE T cells, we did not select a homogeneous group of patients to study based on end-organ involvement. However, none of the patients, at the time of study, had active renal or central nervous system disease. Patients presented with polyarticular non-erosive arthritis $(n=16)$, proteinuria with normal renal function $(n=7)$, pleuritis (4), and lupus malar rash or discoid lupus rash $(n=7)$. Because the study population was heterogeneous, we cannot conclude that the results are representative of all SLE patients. Moreover, it is important to consider that immunosuppressant drugs, such as Pred, may have affected the results. Additional studies including SLE patients not taking medications are necessary to clarify this issue. Although SLE is a strongly gender-biased disorder, the disease occurs in males. The features of SLE in males is often more severe than in female patients (4). Future studies should include male SLE patients to determine if steroid receptor turnover is modified in male patients or accelerated turnover is gender specific. It will be interesting to investigate the interaction of steroid receptors, including the androgen receptor, with 
various cofactors that may alter gene expression and lead to the onset or progression of SLE. A recent study in a breast cancer cell line reported that GR represses ER $\alpha$ action (64). The repression of ER $\alpha$-dependent transcription appeared to be contingent on GR sumoylation, which caused the recruitment of GR and a corepressor complex to ER $\alpha$ occupied enhancers. Greater understanding of how posttranslational modifications of steroid receptors integrate immune-endocrine signaling will help in the molecular understanding of gender-biased autoimmunity. Ultimately, this knowledge will permit greater precision in diagnosis and treatment of patients with SLE and lead to better patient outcomes.

\section{Datasets Are in a Publicly Accessible Repository}

The datasets generated and analyzed in this study can be found on the KUMC public repository: (http://bioinformatics.kumc.edu/ mdms/shares/data/VRider_exp1_raw_leixmWnf1mGhM/).

\section{AUTHOR CONTRIBUTIONS}

VR prepared the T cells, conducted the experiments and IPA analysis, and wrote the manuscript. NA enrolled the SLE

\section{REFERENCES}

1. Cervera R, Khamashta MA, Font J, Sebastiani CD, Gil A, Lavilla P, et al. Systemic lupus erythematosus: clinical and immunologic patterns of disease expression in a cohort of 1,000 patients. The European Working Party on systemic lupus erythematosus. Medicine (Baltimore) (1993) 72:113-24.

2. Ortona E, Pierdominici M, Maselli A, Veroni C, Aloisi F, Shoenfeld Y. Sex-based differences in autoimmune diseases. Ann Ist Super Sanita (2016) 52:205-12. doi:10.4415/ANN_16_02_12

3. Moulton VR, Suarez-Fueyo A, Meidan E, Li H, Mizui M, Tsokos GC. Pathogenesis of human systemic lupus erythematosus: a cellular perspective. Trends Mol Med (2017) 23:615-35. doi:10.1016/j.molmed.2017.05.006

4. Krasselt M, Baerwald C. Sex, symptom severity, and quality of life in rheumatology. Clin Rev Allergy Immunol (2017) 53:1-16. doi:10.1007/s12016-017-8631-6

5. Kassi E, Moutsatsou P. Estrogen receptor signaling and its relationship to cytokines in systemic lupus erythematosus. JBiomed Biotechnol (2010) 2010:317452. doi:10.1155/2010/317452

6. Apostolidis SA, Leiberman LA, Kis-Toth K, Crispin J, Tsokos GC. The dysregulation of cytokine networks in systemic lupus erythematosus. J. Interferon Cytokine Res (2011) 31:769-79. doi:10.1089/jir.2011.0029

7. Karampetsou MP, Comte D, Kis-Toth K, Kyttaris VC, Tsokos GC. Expression patterns of signaling lymphocytic activation molecule family members in peripheral blood mononuclear cell subsets in patients with systemic lupus erythematosus. PLoS One (2017) 12:e0186073. doi:10.1371/journal.pone. 0186073

8. Deng Y, Tsao BP. Updates in lupus genetics. Curr Rheumatol Rep (2017) 19:68. doi:10.1007/s11926-017-0695-Z

9. Rider V, Jones SR, Evans M, Abdou NI. Molecular mechanisms involved in the estrogen-dependent regulation of calcineurin in systemic lupus erythematosus T cells. Clin Immunol (2000) 95:124-34. doi:10.1006/clim.2000.4844

10. Rider V, Jones S, Evans M, Bassiri H, Asfar Z, Abdou NI. Estrogen increases CD40 ligand expression in T cells from women with systemic lupus erythematosus. J Rheumatol (2001) 128:2644-9.

11. Moulton VR, Holcomb DR, Zajdel MC, Tsokos GC. Estrogen upregulates cyclic AMP response element modulator $\alpha$ expression and downregulates interleukin-2 production by human T lymphocytes. Mol Med (2012) 18:370-8. doi:10.2119/molmed.2011.00506

12. Hall JM, Couse JF, Korach KS. The multifaceted mechanisms of estradiol and estrogen receptor signaling. J Biol Chem (2001) 276:36869-72. doi:10.1074/jbc. R100029200 patients, collected the blood samples, and provided patient data. $\mathrm{BK}$ carried out the statistical analyses and contributed to data interpretation. NL, SB, and BF generated the gene lists from the microarray data.

\section{ACKNOWLEDGMENTS}

The authors thank the patients and healthy volunteers for donating blood for this study. We are grateful to Qing Lu (KUMC) for assistance with data analysis.

\section{FUNDING}

Funded in part by the National Institutes of Health (AI49272 to VR), the National Center for Research Resources (SP20RR016475), the National Institute of General Medical Sciences (8P20GM103418), NICHD (HD02528 to K-IDDRC) and the Ronnie K. Swint Memorial Fund for Lupus Research (to VR). The contents of the manuscript are solely the responsibility of the authors and do not necessarily represent the official views of the National Institute of General Medical Sciences of the NIH.

13. Matthews J, Gustafsson J-A. Estrogen signaling: a subtle balance between ER $\alpha$ and ER $\beta$. Mol Interven (2003) 3:281-92. doi:10.1124/mi.3.5.281

14. Mangelsdorf DJ, Thummel C, Beato M, Herrlich P, Schutz G, Umesono K, et al. The nuclear receptor superfamily: the second decade. Cell (1995) 83:835-9. doi:10.1016/0092-8674(95)90199-X

15. Klinge CM. Estrogen receptor interaction with estrogen response elements. Nucleic Acids Res (2001) 29:2905-19. doi:10.1093/nar/29.14.2905

16. McKenna NJ, O’Malley BW. Combinatorial control of gene expression by nuclear receptors and coregulators. Cell (2002) 108:465-74. doi:10.1016/ S0092-8674(02)00641-4

17. Couse JF, Korach KS. Estrogen receptor null mice: what have we learned and where will they lead us? Endocr Rev (1999) 20:358-417. doi:10.1210/ edrv.20.3.0370

18. Feng F, Nylan J, Banyai M, Tatum A, Silverston AE, Gavalchin J. The induction of the lupus phenotype by estrogen is via an estrogen receptor- $\alpha$ dependent pathway. Clin Immunol (2012) 134:226-36. doi:10.1016/j.clim. 2009.10.004

19. Tabor DE, Gould KA. Estrogen receptor alpha promotes lupus in (NZBXNZW) F1 mice in a B cell intrinsic manner. Clin Immunol (2017) 174:41-52. doi:10.1016/ j.clim.2016.10.011

20. Rider V, Li X, Peterson G, Dawson J, Kimler BF, Abdou NI. Differential expression of estrogen receptors in women with systemic lupus erythematosus. J Rheumatol (2006) 33:1093-101.

21. Charn TH, Liu ET, Change EC, Lee YK, Katzenellenboen JA, Katzenellenbogen BS. Genome-wide dynamics of chromatin binding of estrogen receptors alpha and beta: mutual restriction and competitive site selection. Mol Endocrinol (2012) 24:47-59. doi:10.1210/me.2009-0252

22. Grober OM, Mutarelli M, Giurato G, Ravo M, Cicatiello L, Rosaria De Filippo M, et al. Global analysis of estrogen receptor beta binding to breast cancer cell genome reveals an extensive interplay with estrogen receptor alpha for target gene regulation. BMC Genomics (2011) 12:36. doi:10.1186/14712164-12-36

23. Paech K, Webb P, Kuiper GG, Nilsson S, Gustafsson J-A, Kushner PJ, et al. Differential ligand activation of estrogen receptors ER $\alpha$ and ER $\beta$ at AP1 sites. Science (1997) 277:1508-10. doi:10.1126/science.277.5331.1508

24. Gougelet A, Mueller SO, Korach KS, Renoir J-M. Oestrogen receptors pathways to oestrogen responsive elements: the transactivation function-1 acts as the keystone of oestrogen receptor (ER) $\beta$-mediated transcriptional repression of ER $\alpha$. Steroid Biochem Mol Biol (2007) 104:110-22. doi:10.1016/j. jsbmb.2007.03.002 
25. Sentis S, Le Romancer M, Bianchin C, Rostan MC, Corbo L. Sumoylation of the estrogen receptor alpha hinge region regulates its transcriptional activity. Mol Endocrinol (2005) 19:2671-84. doi:10.1210/me.2005-0042

26. Faus H, Haendler B. Post-translational modifications of steroid receptors. Biomed Pharmacother (2006) 60:520-8. doi:10.1016/j.biopha.2006.07.082

27. Anbalagan M, Huderson B, Murphy L, Rowan BG. Post-translational modifications of nuclear receptors and human disease. Nucl Recept Signal (2012) 10:e001. doi:10.1621/nrs.10001

28. Knutson TP, Lange CA. Dynamic regulation of steroid hormone receptor transcriptional activity by reversible SUMOylation. Vitam Horm (2013) 93:227-61. doi:10.1016/B978-0-12-416673-8.00008-3

29. Varshavsky A. The ubiquitin system, autophagy, and regulated protein degradation. Ann Rev Biochem (2017) 86:123-8. doi:10.1146/annurev-biochem061516-044859

30. Weissman AM. Themes and variations on ubiquitylation. Nat Rev Mol Cell Biol (2001) 2:169-78. doi:10.1038/35056563

31. Pichler A, Fatouros C, Lee H, Eisenhardt N. SUMO conjugation-a mechanistic view. BioMol Concepts (2017) 8:13-36. doi:10.1515/bmc-2016-0030

32. Allen CD, Okada T, Cyster JG. Germinal-center organization and cellular dynamics. Immunity (2007) 27:190-202. doi:10.1016/j.immuni.2007.07.009

33. Mosmann TR, Coffman RL. TH1 and TH2 cells: different patterns of lymphokine secretion lead to different functional properties. Annu Rev Immunol (1989) 7:145-73. doi:10.1146/annurev.iy.07.040189.001045

34. Breitfeld D, Ohl L, Kremmer E, Ellwart J, Sallusto F, Lipp M, et al. Follicular $\mathrm{B}$ helper T cells express CXC chemokine receptor 5 , localize to B cell follicles, and support immunoglobulin production. J Exp Med (2000) 192:1545-52. doi:10.1084/jem.192.11.1545

35. Ueno H, Banchereau J, Vinuesa CG. Pathophysiology of T follicular helper cells in humans and mice. Nat Immunol (2015) 16:142-52. doi:10.1038/ni.3054

36. Mesquita D Jr., Cruvinel WM, Resende LS, Mesquita FV, Silva NP, Câmara NO, et al. Follicular helper T cell in immunity and autoimmunity. Braz J Med Biol Res (2016) 49:e5209. doi:10.1590/1414-431X20165209

37. Eivazi S, Bagheri S, Hashemzadeh MS, Ghalavand M, Qamsari ES, Dorostkar R, et al. Development of $\mathrm{T}$ follicular helper cells and their role in disease and immune system. Biomed Pharmacother (2016) 84:1668-78. doi:10.1016/j.biopha. 2016.10.083

38. Ettinger RS, Kuchen S, Lipsky PE. The role of IL-21 in regulating B-cell function in health and disease. Immunol Rev (2008) 223:60-86. doi:10.1136/ ard.2008.098400

39. Ma CS, Deenick EK, Batten M, Tangye SG. The origins, function, and regulation of T follicular helper cells. J Exp Med (2012) 209:1241-53. doi:10.1084/ jem.20120994

40. Bossaller L, Burger J, Draeger R, Grimbacher B, Knoth R, Plebani A, et al. ICOS deficiency is associated with a severe reduction of CXCR5+CD4 germinal center Th cells. J Immunol (2006) 77:4927-32. doi:10.4049/jimmunol.177. 7.4927

41. Walters E, Rider V, Abdou NI, Greenwell C, Svojanovsky S, Smith P, et al. Estradiol targets $\mathrm{T}$ cell signaling pathways in human systemic lupus. Clin Immunol (2009) 133:428-36. doi:10.1016/j.clim.2009.09.002

42. Abdou NI, Rider V, Greenwell C, Li X, Kimler BF. Fulvestrant (Faslodex), an estrogen selective receptor downregulator, in therapy of women with systemic lupus erythematosus. Clinical, serologic, bone density, and T cell activation marker studies: a double-blind placebo-controlled trial. J Rheumatol (2008) 35:797-803.

43. Tan EM, Cohen AS, Fries JF, Masi AT, McShane DJ, Rothfield NF, et al. The 1982 revised criteria for the classification of systemic lupus erythematosus. Arthritis Rheum (1982) 25:1271-7. doi:10.1002/art.1780251101

44. Ebner P, Versteeg GA, Ikeda F. Ubiquitin enzymes in the regulation of immune responses. Crit Rev Biochem Mol Biol (2017) 52:425-60. doi:10.1080/ 10409238.2017

45. Alarid ET. Lives and times of nuclear receptors. Mol Endocrinol (1981) 20:1972-81. doi:10.1210/me.2005-0481

46. Nawaz Z, Lonard DM, Dennis AP, Smith CL, O’Malley BW. Proteasomedependent degradation of the human estrogen receptor. Proc Natl Acad Sci U S A (1999) 96:1858-62. doi:10.1073/pnas.96.5.1858

47. Lonard DM, Nawaz Z, Smithe CL, O'Malley BW. The $26 \mathrm{~S}$ proteasome is required for estrogen receptor- $\alpha$ and coactivator turnover and for efficient estrogen receptor- $\alpha$ transactivation. Mol Cell (2000) 5:939-48. doi:10.1016/ S1097-2765(00)80259-2
48. Laios I, Journé F, Nonclercq D, Salazar Vidal D, Toillon RA, Laurent G, et al. Role of the proteasome in the regulation of estrogen receptor alpha turnover and function in MCF-7 breast carcinoma cells. J Steroid Biochem Mol Biol (2005) 94:347-59. doi:10.1016/j.jsbmb.2005.02.005

49. Bhatt S, Xiao Z, Meng Z, Katzenellenbogen BS. Phosphorylation by p38 mitogen-activated protein kinase promotes estrogen receptor $\alpha$ turnover and functional activity via the SCFSkp2 proteasomal complex. Mol Cell Biol (2012) 32:1928-43. doi:10.1128/MCB.06561-11

50. Le Drean Y, Mincheneau N, Le Goff P, Michel D. Potentiation of glucocorticoid receptor transcriptional activity by sumoylation. Endocrinology (2002) 143:3482-9. doi:10.1210/en.2002-220135

51. Kobayashi S, Shibata H, Yokota K, Suda N, Murai A, Kurihara I, et al. FHL2, UBC9, and PIAS1 are novel estrogen receptor $\alpha$ interacting proteins. Endocr Res (2004) 30:617-21. doi:10.1081/ERC-200043789

52. Ying S, Dunnebier T, Si J, Hamann U. Estrogen receptor alpha and nuclear factor Y coordinately regulate the transcription of the SUMO-conjugating UBC9 gene in MCF-7 breast cancer cells. PLoS One (2013) 13:e75695. doi:10.1371/ journal.pone.0075695

53. Ding X, Wang A, Ma X, Demarque M, Jin W, Xin H, et al. Protein SUMOylation is required for regulatory T cell expansion and function. Cell Rep (2016) 16:1055-66. doi:10.1016/j.celrep.2016.06.056

54. Wang A, Ding X, Demarque M, Liu X, Pan D, Xin H, et al. Ubc9 is required for positive selection and late-stage maturation of thymocytes. J Immunol (2017) 198:3461-70. doi:10.4049/jimmunol.1600980

55. Miranda TB, Voss TC, Sung MH, Baek S, John S, Hawkins M, et al. Reprogramming the chromatin landscape: interplay of the estrogen and glucocorticoid receptors at the genomic level. Cancer Res (2013) 73:5130-9. doi:10.1158/0008-5472.CAN-13-0742

56. Karmakar S, Jin Y, Nagaich AK. Interaction of glucocorticoid receptor (GR) with estrogen receptor (ER) alpha and activator protein 1 (AP1) in dexamethasone-mediated interference of ERalpha activity. J Biol Chem (2013) 288:24020-34. doi:10.1074/jbc.M113

57. West D, Pan D, Tonsing-Carter EU, Hernandez KM, Pierce CF, Styke SC, et al. GR and ER coactivation alters the expression of differentiation genes and associates with improved ER+ breast cancer outcome. Mol Cancer Res (2016) 14:707-19. doi:10.1158/1541-7786.MCR-15-0433

58. Arango-Lievano M, Jeanneteau F. Timing and crosstalk of glucocorticoid signaling with cytokines, neurotransmitters and growth factors. Pharmacol Res (2016) 113:1-17. doi:10.1016/j.phrs.2016.08.005

59. Haynes NM, Allen CD, Lesley R, Ansel KM, Killeen N, Cyster JG. Role of CXCR5 and CCR7 in follicular Th cell positioning and appearance of a programmed cell eath gene-1high germinal center-associated subpopulation. J Immunol (2007) 179:5099-108. doi:10.4049/jimmunol.179.8.5099

60. Vinuesa CG, Tangye SG, Moser B, Mackay CR. Follicular B helper T cells in antibody responses and autoimmunity. Nat Rev Immunol (2005) 5:853-65. doi:10.1038/nri1714

61. Linterman MA, Rigby RJ, Wong RK, Yu D, Brink R, Cannons JL, et al. Follicular helper T cells are required for systemic autoimmunity. J Exp Med (2009) 206:561-76. doi:10.1084/jem.20081886

62. Le Coz C, Joublin A, Pasquali JL, Korganow AS, Dumortier H, Monneaux F. Circulating TFH subset distribution is strongly affected in lupus patients with an active disease. PLoS One (2013) 19:e75319. doi:10.1371/journal. pone. 0075319

63. Mackay CR. Follicular homing Thelper (Th) cells and the Thy1/Th2 paradigm. J Exp Med (2000) 192:F31-4. doi:10.1084/jem.192.11.F31

64. Yang F, Ma Q, Liu Z, Li W, Tan Y, Jin C, et al. Glucocorticoid receptor: megatrans switching mediates the repression of an ER $\alpha$-regulated transcriptional program. Mol Cell (2017) 66:321-31. doi:10.1016/j.molcel2017.03019

Conflict of Interest Statement: The authors declare that there is no conflict of interest that could be perceived as prejudicing the impartiality of the research reported.

Copyright (๑) 2018 Rider, Abdou, Kimler, Lu, Brown and Fridley. This is an openaccess article distributed under the terms of the Creative Commons Attribution License (CC BY). The use, distribution or reproduction in other forums is permitted, provided the original author(s) and the copyright owner are credited and that the original publication in this journal is cited, in accordance with accepted academic practice. No use, distribution or reproduction is permitted which does not comply with these terms. 